\title{
Práticas e vivências de avaliação das aprendizagens dos alunos: refletindo com professoras pedagogas
}

\section{Practices and experiences evaluation of students learning: reflecting with teachers}

\author{
Dilva Bertoldi Benvenutti \\ Maria Cristina Pansera de Araújo \\ Nadiane Feldkercher ${ }^{* * *}$
}

\section{Resumo}

Com o pressuposto de que o processo de avaliação da aprendizagem pode constituir o professor reflexivo, crítico, autônomo, dialógico, que respeita e valoriza sujeitos em formação, neste trabalho, objetivamos analisar os processos avaliativos desenvolvidos por professoras pedagogas atuantes nos anos iniciais do ensino fundamental da educação básica. A pesquisa caracterizou-se como qualitativa e descritiva. Foi realizada com 24 professoras, egressas do Curso de Pedagogia da Universidade do Oeste de Santa Catarina - Unoesc Maravilha (2004-2008). Os instrumentos para obtenção dos dados foram: questionário semiestruturado, grupo focal e fórum on-line. As reflexões embasaram-se, essencialmente, em Paulo Freire. Entendemos que o sistema tradicional de avaliação ignora as diferenças das crianças, as possibilidades de acompanhamento individual, controlando de forma genérica o cumprimento dos conteúdos escolares - o que suscita novas proposições. O professor é carregado de experiências que influenciam as escolhas por estratégias avaliativas e seus sentimentos no momento da avaliação.

Palavras-chave: Aprendizagem. Avaliação. Diálogo. Processo. Reflexão.

\section{Abstract}

The principle is that the learning assessment process can constitute a reflective, critical, autonomous and dialogic teacher, who respects and valorizes all the subjects in formation. In this study the objective is to analyze the evaluation processes developed by teachers who work in Elementary School of Basic Education. It was a qualitative and descriptive research and it was carried out with twenty-four teachers from elementary school and graduated by Pedagogy Course of Unoesc Maravilha, SC (2004-2008). The instruments to obtain the data were a semi-structured questionnaire, a focus group and also an online forum. The reflections were based essentially on Paulo Freire. The traditional system of evaluation ignores the children's differences and the possibilities of individual accompaniment, controlling in a generic way the fulfillment of the school subjects, which needs new propositions. The teacher is loaded with experiences, being that strategies have been adopted and their feeling when evaluating can influence on the formative process.

Keywords: Learning. Evaluation. Dialogue. Process. Reflection.

Recebido em 16/05/2017 - Aprovado em 27/11/2017

http://dx.doi.org/10.5335/rep.v25i1.8037

Doutora em Educação nas Ciências na Universidade Regional do Noroeste do Estado do Rio Grande do Sul. Professora do Curso de Pedagogia da Universidade do Oeste de Santa Catarina, São Miguel do Oeste, SC. E-mail: dilva. benvenutti@unoesc.edu.br

** Doutora em Genética e Biologia Molecular. Professora do Programa Pós-Graduação em Educação nas Ciências na Universidade Regional do Noroeste do Estado do Rio Grande do Sul. E-mail: pansera@unijui.edu.br

*** Doutora em Educação pela Universidade Federal de Pelotas. Professora na Universidade do Oeste de Santa Catarina, vinculada ao Programa de Pós-Graduação em Educação, campus Joaçaba. E-mail: nadianef@gmail.com 


\section{Introdução ao diálogo}

A avaliação é uma ação constitutiva do homem, que, de modo consciente ou não, faz juízo e atribui valor, interferindo de alguma forma em escolhas e posicionamentos diante do mundo. Essa atitude vem, ao longo dos anos, marcando o processo de ensino e de aprendizagem, determinando quem são os sujeitos promovidos e quem deve permanecer no mesmo lugar. Essa rotina é chamada pelo sistema educacional de aprovação ou reprovação.

Somos seres humanos marcados por vivências, sejam elas positivas ou não, que constroem significado e nos acompanham nas experiências posteriores, definindo sentido e roupagem às ações futuras. Assim, compreendemos que podemos refletir sobre nossas vivências, pois, segundo Freire (2003, p. 30-31), é por meio da reflexão que o ser humano pode se desvencilhar do seu estado de "consciência transitiva ingênua", extrapolando para a condição de consciência crítica, que é impulsionadora de um estado de mudança para realidade posta.

É nesse contexto que situamos e sugerimos as reflexões sobre as vivências avaliativas, no intuito de ultrapassar a mera repetição, sendo que entendemos que ações avaliativas refletidas trazem um novo olhar sobre o processo de avaliação das aprendizagens e podem tornar-se experiências significativas de vida.

Para Freire, “[...] a práxis é reflexão e ação dos homens sobre o mundo para transformá-lo. Sem ela, é impossível a superação da contradição opressor-oprimido" (2005, p. 38). Dar voz e vez a quem está desenvolvendo práticas avaliativas visa respeitar a singularidade dos sujeitos, abrindo canal de diálogo e comunicação entre pares, que juntos socializam vivências e constroem novos saberes. O compartilhamento de vivências e experiências singulares de avaliação permite reflexões coletivas que enriquecem as discussões e a formação desses professores avaliadores.

O protagonismo do professor decorre da inserção na compreensão das influências formativas que possibilitam as escolhas de outros encaminhamentos e estratégias avaliativas na sua atuação profissional, pontos que significam construção do pensamento, linguagem e consciência, e não mera reprodução da realidade vivenciada.

A avaliação escolar é um elemento importante, pois oportuniza a investigação, a reflexão e a qualificação dos processos pedagógicos, valorizando os sujeitos da aprendizagem (BENVENUTTI, 2016).

É preciso cessar as vozes e práticas arcaicas e ultrapassadas, olhando para a avaliação como algo que retroalimenta o processo de ensino-aprendizagem. Avaliação vista como ato de cuidado, amor e comprometimento oferece sustentáculo 
para superação da ignorância, de limites e barreiras encontrados no processo de construção do conhecimento. É uma espécie de escada, que permite retomada e avanços, movimento significativo que estimula professor e aluno a vibrar com as conquistas e juntos prosseguir. Como destaca Freire: "Diferentemente dos outros animais, que são apenas inacabados, mas não são históricos, os homens se sabem inacabados. Têm a consciência de sua inconclusão [...]" (2005, p. 83-84). Essa capacidade de reconhecer-se não pronto transforma a condição do sujeito, modificando os encaminhamentos e as possibilidades do processo educativo vigente.

A rotina convencionada no processo avaliativo escolar gera mitos e preconceitos que rotulam, manipulam e impedem avanços no desenvolvimento integral e nas aprendizagens dos alunos. Rebuscar vivências para transformar em experiências é uma tomada de decisão que permite avanços em termos de reflexões teóricas e metodológicas sobre a avaliação.

Neste estudo, buscamos promover reflexões a respeito das vivências avaliativas das professoras pesquisadas. $\mathrm{O}$ estudo apresentado pautou-se na pesquisa qualitativa, em que as abordagens contribuem na análise da realidade social, gerando opiniões e interpretações de comportamentos e atitudes produzidos pelos sujeitos da pesquisa. Nessa direção, o estudo objetiva analisar os processos avaliativos desenvolvidos por professoras pedagogas atuantes nos anos iniciais do ensino fundamental da educação básica, bem como identificar e analisar as estratégias utilizadas para a recuperação da aprendizagem de alunos dos anos iniciais adotadas pelas professoras pedagogas, identificando os sentimentos das professoras no momento de avaliar.

Participaram da investigação 24 professoras, 8 para cada instrumento: questionário semiestruturado (PQ), fórum on-line (PF) e grupo focal (GF). Eram todas egressas do Curso de Pedagogia da Universidade do Oeste de Santa Catarina Unoesc Maravilha (matriz 2004-2008), atuantes nos anos iniciais do ensino fundamental nos anos de 2014 e 2015. A fim de garantir a autoria das afirmações e o anonimato das respondentes, as professoras foram designadas por PQ1 a PQ8, quando o excerto apresentado foi retirado das respostas ao questionário; PF1 a PF8, aos fragmentos do fórum on-line; e PGF1 a PGF8, aos extratos do grupo focal. As falas das participantes, identificadas por PQ, PF ou PGF, conforme sua origem - questionário, fórum on-line e grupo focal -, são apresentadas em itálico, quando analisadas no texto.

Oito professoras pedagogas preencheram o questionário, que, segundo Gil, “[...] é a técnica de investigação composta por um número mais ou menos elevado de questões apresentadas por escrito às pessoas, tendo por objetivo o conhecimento de opiniões, crenças, sentimentos, interesses, expectativas, situações vivenciadas, 
etc.” (1999, p. 128). Outras oito envolveram-se na discussão proposta no fórum on-line, um espaço de argumentação que visa à leitura da realidade de forma crítica pelos seus participantes (LOPES, 2007). Por fim, mais oito egressas participaram do grupo focal coletivo, que, segundo Caplan, “[...] é um pequeno grupo de pessoas reunido para avaliar conceitos ou identificar problemas [...] em pesquisas qualitativas" (1990, p. 17).

Justifica-se o estudo por entender a relevância didática, pedagógica e social e a necessidade do conhecimento sobre avaliação, pois muitas práticas dos professores têm sido utilizadas como mecanismos de controle, amedrontamento e seleção social. Logo, olhar para a experiência permite aos sujeitos da pesquisa pensar e comunicar suas ideias, possibilitando, ao mesmo tempo, refletir e ressignificar suas vivências avaliativas de outro lugar: como professor que avalia e que, por muito tempo, foi avaliado.

\section{0 fazer e o sentir das professoras pedagogas nos seus contextos de sala de aula}

As vivências avaliativas incutem a internalização de conceitos, orientam normas, delineiam modelos e norteiam procedimentos. O professor, diante dessa situação, necessita ser provocado a pensar, pois o processo de "ação-reflexão-ação" (SCHÖN, 2000, p. 16) permite mobilizar outras possibilidades de agir, proporcionando aos docentes pertencimento, presença de sujeitos que, coletivamente, constroem caminhos ainda não definidos, próprios e delineados pelos implicados no processo.

As estratégias construídas pelas professoras pedagogas nos anos iniciais do ensino fundamental podem estar baseadas em modelos vivenciados no decorrer de sua formação, que, ao ingressar no contexto da escola, sentem-se desafiadas e passam a cumprir regras traçadas pelo sistema ou a seguir rotinas já instituídas pela instituição. Diante da emergência e da insegurança, a saída pode ser a ação conhecida. Como chama atenção Freire (2006), quando se refere à tomada de consciência, em que o sujeito passa a ter clareza sobre o aspecto dialético da educação, sendo que "[...] a conscientização implica, pois, que ultrapassemos a esfera espontânea de apreensão da realidade, para chegarmos a uma esfera crítica na qual a realidade se dá como objeto cognoscível e na qual o homem assume uma posição epistemológica" (2006, p. 30). A oportunidade de reflexão e conscientização deve fazer parte da formação desse professor. 
A consciência de atos e fatos permite observar e analisar a realidade, propiciando mudança de pensamento e prática. Esse processo de desenvolvimento necessita predispor os sujeitos, possibilitando a superação de um estado condicionado de ser e estar. Essa consciência reflexiva faz o sujeito perceber a intenção, possibilitando pensar e refletir sobre a ação, sendo que o homem, ao expor seu pensamento sobre a intencionalidade da consciência, mostra conhecer a história do problema (FREIRE, 1969).

Nessa direção, o processo de formação universitária pode ajudar o aluno a desenvolver seu potencial criador de pensar e refletir sobre o mundo no qual vive. Como afirma Freire: "É preciso que seja capaz de, estando no mundo, saber-se nele" (2014, p. 19), ou seja, conhecer a forma como o mundo manipula a consciência do ser humano, sentindo-se parte do processo de constituição de si e do ambiente no qual está instituído. Os estudantes serão ensinados, cobrados e regrados, porém, todos esses esforços podem ser imbuídos de desafios, estímulos e significação do que é ensinado. Viver intensamente o percurso torna o processo mais leve e expressivo.

Somente um ser é capaz de sair de seu contexto, de "distanciar-se" dele para ficar com ele; capaz de admirá-lo para, objetivando-o, transformá-lo e, transformando-o pela sua própria criação; um ser que é e está sendo no tempo que é seu, um ser histórico, somente este é capaz, por tudo isso, de comprometer-se (FREIRE, 2014, p. 21).

A partir desse olhar, o intento é conhecer as estratégias adotadas pelas professoras pedagogas para recuperar a aprendizagem dos alunos, entendendo esse processo como necessário, paralelo e processual, exigindo um olhar apurado do professor e dos alunos.

A Lei nº 9.394/1996, que estabeleceu as Diretrizes e Bases da Educação Nacional (LDB), no art. 24, inciso V, alínea "e", trata das regras comuns da organização da educação básica, indicando os critérios de verificação do rendimento escolar, e assevera: "[...] obrigatoriedade de estudos de recuperação, de preferência paralelos ao período letivo, para os casos de baixo rendimento escolar, a serem disciplinados pelas instituições de ensino em seus regimentos" (BRASIL, 1996). Essa prática aperfeiçoa o processo pedagógico, uma vez que a intervenção ocorre ao localizar a dificuldade dos alunos no período em curso.

As estratégias adotadas pelas professoras pedagogas para recuperar a aprendizagem dos alunos apresentam-se no Gráfico 1: 
Gráfico 1 - Estratégias adotadas pelas professoras pedagogas atuantes nos anos iniciais do ensino fundamental no município de Maravilha para recuperar a aprendizagem das crianças com ritmos diferenciados, 2014-2015

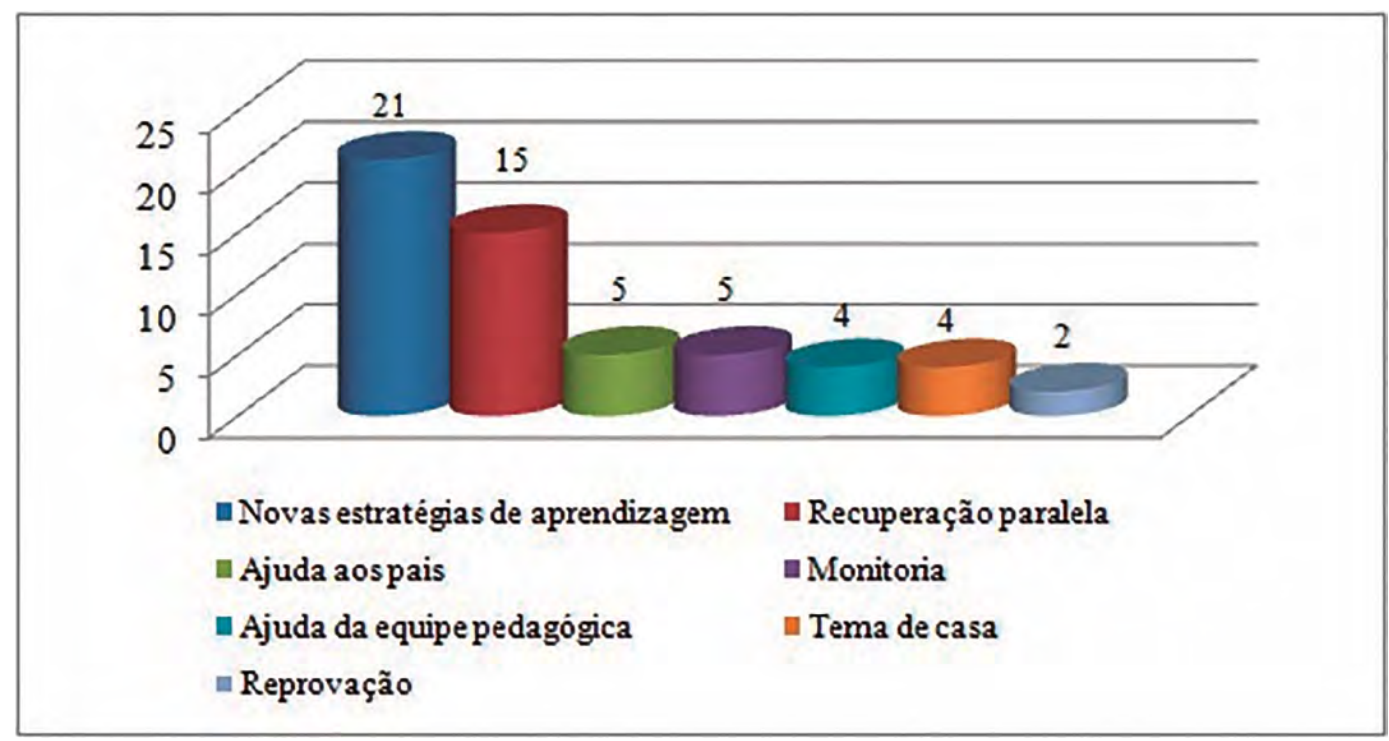

Fonte: dados da pesquisa (2016).

Percebe-se que, entre as alternativas apresentadas, as professoras pedagogas utilizam com mais frequência a elaboração de novas estratégias de aprendizagem e solicitam ajuda aos pais. PQ8 diz: "é feito primeiro uma nova explicação do conteúdo, exercícios de fixação". PF2 complementa: "conversado com a família e feito recuperação de atividades no decorrer das aulas". E PF8 diz: "efetuado atendimento individualizado". Também incluem com menor intensidade a recuperação paralela, a monitoria, o tema de casa e a reprovação. PQ1 afirma que: "Os diferentes níveis de aprendizagem mesclados em grupos têm sido uma excelente ferramenta no processo". Já PQ2 diz que:

Tentamos trabalhar de forma diferenciada, com atividades que não exigem tanto, até "pegarem” bem o que está sendo trabalhado. Como são anos iniciais, por exemplo, na escrita foi trabalhado com caderno de caligrafia, com o desenho da letra e escrita correta, sobre a leitura, foi trabalhado com a leitura individual e em voz alta, cuidando e mostrando os sons, os erros que cometem. Na matemática, com material concreto, material dourado, caixa de ovos para multiplicação e divisão (PQ2).

PQ3 comenta: "mesmo com tantas tentativas para tentar dar conta de atender os objetivos, sinto que para alguns casos ainda foi pouco". Isso mostra o quanto é difícil ensinar e dar conta das diversidades no contexto da sala de aula. É uma 
quantidade de conteúdos que devem ser desenvolvidos, com várias pessoas, em determinado tempo. Isso angustia o professor, que se sente impotente e dividido entre as exigências do sistema e as necessidades individuais de cada aluno.

As famílias precisam ser envolvidas nesse processo, pois o diálogo oportuniza a troca de informações e a possibilidade de assistência e orientação coletiva para aprendizagem. Essa sintonia entre escola e família está assegurada na Lei de Diretrizes da Educação Nacional (Lei no 9.394/1996), art. 2: "A educação, dever da família e do Estado, inspirada nos princípios de liberdade e nos ideais de solidariedade humana, tem por finalidade o pleno desenvolvimento do educando, seu preparo para o exercício da cidadania e sua qualificação para o trabalho" (BRASIL, 1996). O acompanhamento e o incentivo familiar fortalecem os vínculos de cuidado, segurança e controle das ações, além da relevância do afeto e do incentivo para 0 desenvolvimento da criatividade e da autoestima, fatores fundamentais para que ocorram a aprendizagem, o desenvolvimento, a imaginação e a criação.

Constata-se que as professoras pedagogas buscam elaborar várias estratégias para que os alunos aprendam. PGF5 destaca: "Recuperação paralela e elaboração de novas estratégias", para atender ao previsto na LDB/1996 no que se refere à recuperação efetuada no decorrer do processo. Assim, o professor torna-se pesquisador, com ações pautadas na reflexão permanente no transcurso da aprendizagem. O envolvimento e o comprometimento do professor fazem grande diferença, pois os alunos se sentem cuidados, vistos e valorizados. A elaboração de novas estratégias exige do professor conhecimento teórico-prático, vivências e experiências refletidas sobre sua atuação. Este é o papel da formação inicial e continuada: propiciar espaço e tempo para que os professores, coletivamente, possam refletir sobre a ação e detectar possibilidades de qualificação do ensino e da aprendizagem.

Verificamos que existe preocupação das professoras pedagogas em atender e respeitar as diferenças individuais. Freire ressalta que: “[...] o caminho para assumir-se como maioria está em trabalhar as semelhanças entre si e não só as diferenças e, assim, criar a unidade na diversidade" (1993, p. 154). Entendemos que, nessa manifestação, o professor poderá trabalhar a partir do caráter mediador da avaliação, que prevê todos os passos e os tempos dos sujeitos que aprendem, pois as condições e os ritmos diferenciados da aprendizagem embelezam a trajetória, aproximam coletivos, conferindo dinâmica e possibilidade de reflexão na própria ação.

Estar interessado e sentir-se parte do processo significam entender os novos olhares, estar em condições de perceber semelhanças e diferenças, possibilidades outras no seu fazer e nas aprendizagens expressas pelos alunos. Essa capacidade de análise reflexiva é o suporte para encaminhamentos que superam e qualificam as experiências vividas. A formação inicial e continuada do professor é o alicerce 
dessa mudança de prática, pois oportuniza a exposição de experiências; o conhecido torna-se analisável, possibilitando a evolução do pensamento e da ação.

Ensinar, avaliar e aprender são atos complexos e desafiadores, logo, é importante saber como as professoras pedagogas reconhecem e sentem esse momento de avaliar. O Gráfico 2 demonstra o que elas expressaram sobre o que sentem quando avaliam:

Gráfico 2 - Sentimentos das professoras pedagogas do município de Maravilha, SC, no momento de avaliar as crianças dos anos iniciais do ensino fundamental, 2014-2015

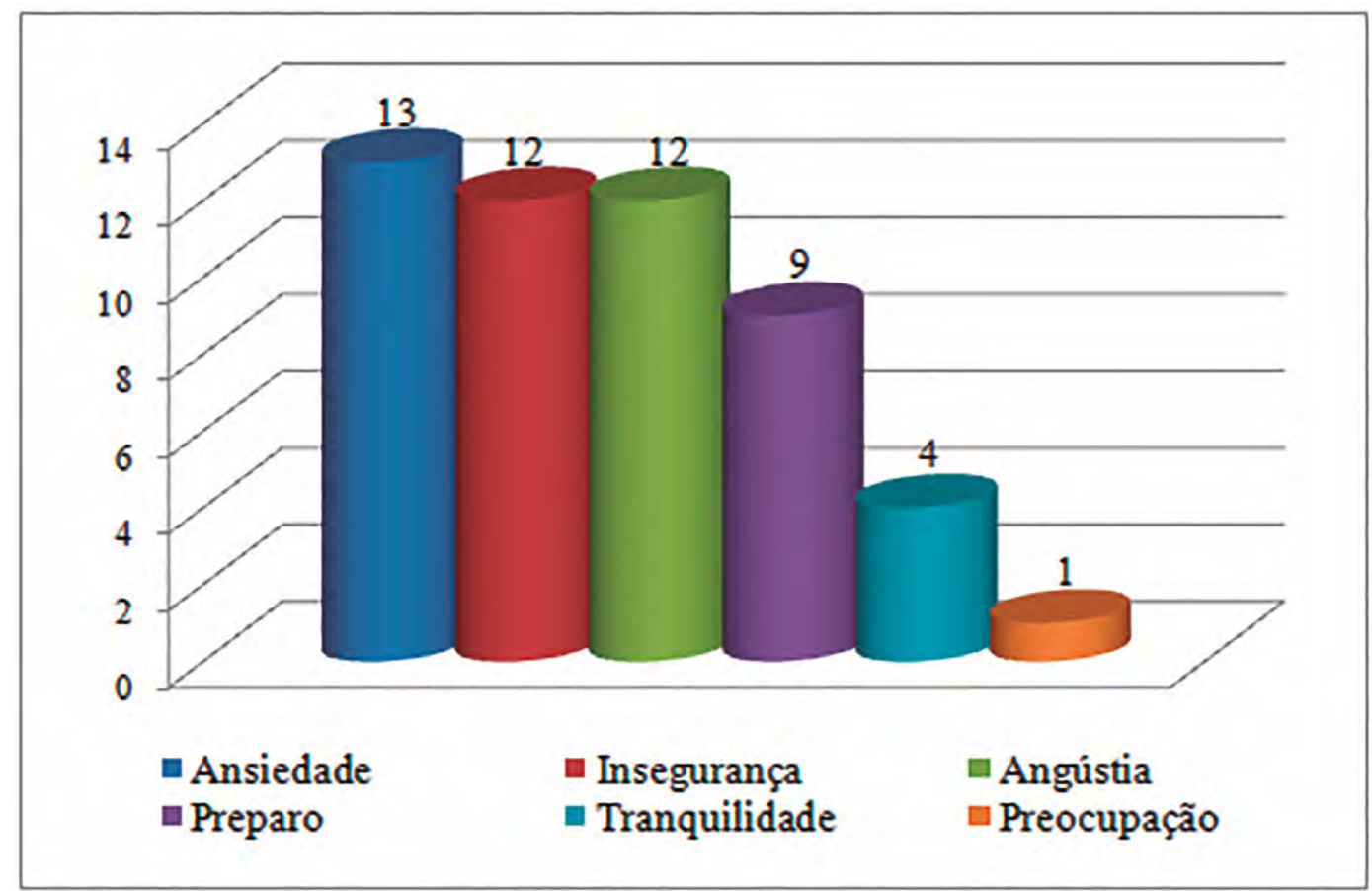

Fonte: dados da pesquisa (2016).

Avaliar é perceber se os alunos realmente estão aprendendo e se o processo de ensino foi eficaz. Essa atividade é inerente ao ato educativo, cabe ao professor se dar conta desse processo e entender que, para avaliar, é preciso ter coragem, conhecimento, organização, humildade e amor pelo que se faz. Pois, o simples fato de ser naturalmente curioso, não se conformar em ser somente espectador, saber que pelo pensamento e pela ação pode se tornar sujeito da própria existência e ajudar a transformar o mundo (FREIRE, 2005), já é motivo suficiente para prosseguir. 
Nesse sentido, constata-se, no decorrer da pesquisa, o grande número de professoras pedagogas que ficam ansiosas, inseguras e angustiadas no momento de avaliar (PQ2, PQ3 e PQ4).

Não me sinto muito preparada, apesar de ter estudado bastante sobre avaliação na universidade e em formações continuadas, é um assunto que sempre necessita ser trabalhado, é complicado; de certa forma a avaliação é uma arma na mão de um professor, cada criança é única, se desenvolve e aprende diferente. Encontro dificuldade em avaliar, consigo perceber os avanços e as dificuldades de cada aluno, mas na hora de colocar no papel, dar a famosa "nota", é que me sinto insegura de talvez estar sendo injusta com um aluno ou com o resto da turma dependendo da situação (PQ2).

Em determinadas situações me sinto tranquila, mas com alguns alunos com dificuldade de aprendizagem fico angustiada (PQ3).

Na maioria das vezes me sinto preocupada, por mais que fiz o possível para ajudar o aluno, temo em ser injusta na hora de avaliar (PQ4).

Pautadas pelo desejo de justiça, as professoras assumem o ato como difícil e pesado, reconhecendo que essa não é uma tarefa fácil de ser desenvolvida. PQ7 destacou: "O momento da avaliação requer atenção, reflexão e análise sobre os objetivos propostos, o desenvolvimento, as metodologias utilizadas, o aluno, a aprendizagem e a avaliação". E PQ8 relatou: "tenho medo de avaliar de modo equivocado". A fobia impede o professor de pensar com mais serenidade e tranquilidade sobre o processo. Para Freire, "[...] a assunção de nós mesmos não significa a exclusão dos outros. É a 'outredade' do 'não-eu' ou do 'tu', que me faz assumir a radicalidade de meu eu" (2005, p. 46). Avaliar o outro é compromisso, cabe a mim, pelo menos, sentir-me parte do processo e respeitar o outro na sua subjetividade. O medo e a insegurança em demasia podem provocar desvios nos encaminhamentos metodológicos do professor, interferindo negativamente no processo de aprendizagem dos alunos dos anos iniciais da educação básica.

Isso nos faz reconhecer que não existem caminhos totalmente seguros para avaliar, pois vivemos intensamente a era da oscilação, o século XX derrubou a previsão de futuro, caíram impérios que pensavam perpetuar-se eternamente. A educação está unida à incerteza, às reações e às ações imprevisíveis. É necessário preparar os estudantes para pensar e agir diante do imprevisto, pensar a incerteza, intervir no futuro através do presente, pesquisando e analisando as experiências vividas. É na tentativa e na valorização do erro que talvez estejam outras possibilidades. Avaliar é mapear dificuldades e traçar novos jeitos de caminhar.

Vivemos um tempo de medos, angústias e controles, sentimentos que complicam e impedem o professor de entregar-se intensamente ao processo de criação de outros jeitos de avaliar. Dessa forma, o resultado no uso de um instrumento de 
avaliação que deveria subsidiar, investigar e qualificar o processo de aprendizagem passa a afligir o professor e a angustiar o aluno. O processo avaliativo é complexo, visto que exige do professor investimento no que diz respeito ao planejamento e ao domínio teórico-prático do que essa ação significa. Para Freire, “[...] como professor não me é possível ajudar o educando a superar sua ignorância se não supero permanentemente a minha. Não posso ensinar o que não sei” (2005, p. 107). A experiência consciente pode contribuir para esse processo, pois possibilita tomar nas mãos uma responsabilidade que é do professor, ressaltando que essas decisões poderão definir o destino de muitos alunos, que, estimulados ou desanimados, direcionam seus projetos de vida.

Somos o resultado do que fizeram e fazem conosco e também responsáveis por aquilo que continuamos fazendo com nós mesmos. Nesse contexto, ressaltamos a importância da reflexão das vivências avaliativas no decorrer da formação, pois insegurança, angústia, medo e ansiedade podem ser provenientes de vivências não refletidas ou da falta de preparação teórico-prática do professor.

Os medos dos alunos e dos professores precisam ser enfrentados, caso contrário, o ato avaliativo será inócuo e sem sentido, pois a escola é lugar de constituição de relações de confiança, bem-estar e felicidade. Só assim os sujeitos podem viver intensamente o processo, ampliando suas relações com o mundo.

Conforme Formosinho: "A docência é uma profissão que se aprende pela vivência da discência. Todos os futuros professores têm no seu longo currículo discente uma aprendizagem de que emergem teorias e representações acerca do que é o ser professor" (2009, p. 98). Constituímo-nos constantemente. Assim, a profissão de professor traz um diferencial, se comparada a outras profissões, pois, segundo Formosinho, "[...] um estudante de um curso de formação de professores já praticou o ofício de aluno durante 12-15 anos, já observou dezenas de professores e experienciou milhares de aulas" (2009, p. 99). As reflexões acerca das vivências são fundamentais, pois podem estruturar as experiências inerentes ao exercício da profissão. Como afirma Formosinho: "Cabe à Instituição de formação analisar estas aprendizagens e incorporá-las nos processos formativos, de modo a (re)construir a imagem que os estudantes já têm do ofício de professor" (2009, p. 100).

A ação e os sentimentos das professoras pedagogas podem estar interligados com as vivências e práticas de avaliar.

\section{Professoras pedagogas: entre vivências e práticas de avaliar}

Diante do estado de insegurança, ansiedade e angústia demonstrado pelas professoras pedagogas no momento de avaliar (Gráfico 2), faz-se necessário pensar como as vivências podem internalizar conceitos, delinear normas, modelos e pro- 
cedimentos. A busca de memórias e vivências das futuras professoras pedagogas pode ser um caminho de reflexão e diálogo sobre essas práticas.

Como destaca Freire:

Não há técnicas neutras que possam ser transplantadas de um contexto a outro. A alienação do profissional não lhe permite perceber a obviedade. [...] explicam a inibição da criatividade [...] geralmente produz uma timidez, uma insegurança, um medo de correr o risco da aventura de criar, sem o qual não há criação. [...]. Daí o homem alienado, inseguro e frustrado [...] verá as coisas mais na superfície que em seu interior (2014, p. 30-31).

É relevante que o curso de Pedagogia (re)conheça as vivências avaliativas dessas acadêmicas, possibilitando a "ação-reflexão-ação" (SCHÖN, 2000, p. 16), evitando a transferência de experiências vivenciadas negativamente durante sua formação. É urgente e necessário entender a função da avaliação como prática mediadora autônoma, que impulsiona o crescimento, a construção de indivíduos críticos e capazes de transformar o mundo em que vivem.

É imprescindível que não se reproduza um tipo de avaliação que impulse o medo e o receio de ser avaliado, reprovado e excluído. É perigoso normalizar um processo de avaliação que assusta, classifica e monopoliza. Aprender é um ato de coragem, alegria e vida. Vida não é submissão, negligência e amedrontamento. $O$ medo esvazia o sentido da educação e atropela um tempo que poderia ser significativo e feliz. Podemos fazer uma aproximação dessas nossas perspectivas como a ponderação de Freire (2014, p. 34) que compreende o homem como "[...] um ser na busca constante de ser mais e, como pode fazer esta autorreflexão, pode descobrir-se como um ser inacabado, que está em constante busca". Segundo o autor, essa seria a raiz da educação. Em nossa concepção percebemos os professores como seres e profissionais inacabados e, portanto, em um contínuo processo de aprimoramento de suas práticas, inclusive suas práticas avaliativas.

As experiências jamais poderão ser generalizadas, pois dependem do professor, dos encaminhamentos efetuados pela gestão e do sistema escolar. É imprescindível negar a avaliação como estagnação, reprodução e classificação, em que os alunos só estudam para realizar provas e dar conta de um sistema quantitativo e classificatório, que não inclui nem ensina.

A práxis é necessária nesse contexto, pois ela não é mera prática: “A reflexão crítica sobre a prática se torna uma exigência da relação Teoria/Prática sem a qual a teoria pode ir virando blábláblá, e a prática, ativismo [...]” (FREIRE, 2003, p. 22).

O perigo está em bloquear a capacidade criadora do professor, que aprende, em sala de aula, um cabedal de técnicas e metodologias, como se fosse um receituário, levando-o a reproduzir sem criticidade. Quando lhe é oportunizado expor suas vivências, surge a possibilidade de questionamento e reflexão, perspectivas 
coletivas e diferenciadas, pensamentos que vão constituindo consciência com olhares práticos.

Uma prática reflexiva competente do professor permite encaminhamentos coletivos, possibilitando melhorar não só as relações na sala de aula, mas também interferir nos contextos sociais mais amplos. Refletir, no decorrer da ação, possibilita o desenvolvimento do pensamento e de outras intervenções. Eis a concepção "bancária" de educação: "[...] fora da busca, fora da práxis, os homens não podem ser" (FREIRE, 2005, p. 66).

Pensar sobre a ação parece ser importante para ressignificar o fazer pedagógico e traçar outras possibilidades de intervenções, reconhecendo que uma proposta reflexiva pode qualificar o processo de formação de professores, permitindo ampliar a capacidade de enfrentar incertezas, desafios e problemas complexos inerentes ao contexto escolar.

As professoras pedagogas pesquisadas reconhecem a importância dessa etapa de formação, entendendo esse espaço como possibilidade de reflexão e conscientização, percebendo-se capazes de pensar e articular saberes científicos e pedagógicos.

É um processo de desenvolvimento que necessita predispor os sujeitos, possibilitando a superação de um estado condicionado. Essa consciência reflexiva faz o sujeito perceber a intenção, o que permite pensar e refletir sobre a ação, sendo que o homem, ao expor seu pensamento sobre a intencionalidade da consciência, mostra conhecer a história do problema (FREIRE, 1969).

O controle efetuado pelo sistema e a rotina que assola a vida diária do professor no contexto da sala de aula, muitas vezes, exigem que se mascare o sentido da avaliação, pois estipulam prazos e exigem domínio de habilidades e competências, que a maioria dos alunos, em um pequeno espaço de tempo, tem dificuldades de cumprir.

O processo de disciplinamento delineia um jeito próprio de modelar e monitorar os sujeitos. Muitas vezes, a avaliação assusta, amedronta e mantém os indivíduos submissos e controlados. Calar e obedecer podem ser a regra para ser bom aluno. Essa manipulação pode interessar aos que se dizem "neutros" ou que não querem enfrentar conflitos ou discussões de ideias. De acordo com Freire:

A neutralidade frente ao mundo, frente ao histórico, frente aos valores, reflete apenas o medo que se tem de revelar o compromisso. Esse medo quase sempre resulta de um "compromisso" contra os homens, contra sua humanização, por parte dos que se dizem neutros (2014, p. 22).

O silêncio, as angústias e os sentimentos de alunos e professores, escondidos entre os muros escolares, fazem com que as regularidades educacionais sejam cumpridas e reproduzidas, porém, muito pouco entendidas e refletidas. 
O que importa, na formação docente, não é a repetição mecânica do gesto, este ou aquele, mas a compreensão do valor dos sentimentos, das emoções, do desejo, da insegurança a ser superada pela segurança, do medo que, ao ser educado, vai gerando a coragem (FREIRE, 1996, p. 26).

Quando não se pensa, nem se questionam as rotinas e práticas imbuídas nos contextos escolares, reproduzem-se e instalam-se redes de subordinação e amedrontamento. As muralhas só se rompem diante da reflexão, do questionamento e da conscientização. Uma prática embasada no bem-querer e na cidadania.

\section{Prática avaliativa numa perspectiva cidadã e de benquerença}

O professor constitui-se por experiências que nem sempre são suas, pois, no decorrer do seu percurso formativo, vivenciou práticas, normas e regras de outros, organizadas num sistema tradicional, que, na maioria das vezes, ignora possibilidades da construção de novos conhecimentos e controla, de forma genérica, o cumprimento dos conteúdos escolares.

As profissionais pesquisadas apontaram várias estratégias para avaliar as crianças que apresentam dificuldade de aprender. Em contrapartida, quando avaliam, ficam ansiosas, inseguras e angustiadas. A avaliação, quando entendida como processo, é uma ferramenta que pode auxiliar e mediar o conhecimento numa perspectiva cidadã, emancipatória e amorosa, qualificando e valorizando os sujeitos da aprendizagem. Entende-se que a profissão de professor é feita de saberes teóricos e práticos, com o objetivo de significar e melhorar a vida dos alunos.

As vivências refletidas das professoras pedagogas podem servir de orientação para fazer diferente, perceber o insólito e interferir de forma dessemelhante. A atividade avaliativa é complexa, mas relevante. Faz-se necessário "sacolejar" as vivências, caso contrário, elas se arrastam e se reproduzem sem perspectiva de mudança. Aponta-se para um processo de avaliação da aprendizagem numa perspectiva reflexiva, crítica, autônoma, dialógica, que respeita e valoriza sujeitos em formação.

As vivências avaliativas desenvolvidas na escola possuem força inigualável na formação do professor, pois, desde muito cedo, já constatam que a nota é que vai decidir o destino escolar. Assim, o curso de Pedagogia pode possibilitar aos sujeitos da aprendizagem a oportunidade de olhar para dentro e para fora de si mesmos, de modo que o professor possa entender-se como parte do processo, responsável em movimentar um conhecimento recíproco e necessário, para que ambos (professor e aluno) possam se desenvolver. 
É relevante duvidar das certezas, obviedades e evidências. A incerteza, a sutileza e o bom senso ajudam o professor a seguir a viela, duvidando do vivido, do percebido e do constatado. Este olhar cuidadoso e amoroso oferece um ambiente de confiança e bem-querer entre professor e aluno, percebendo a avaliação como um movimento necessário para a aprendizagem. Não basta elaborar instrumentos diferenciados de avaliação, admitir estar inseguro e com medo de avaliar, o professor precisa posicionar-se e sentir-se parte do processo.

Desejamos, com este estudo, desacomodar verdades e promover motivos para diálogos e reflexões que permeiam o contexto escolar e a coletividade de professores dos anos iniciais do ensino fundamental. A intenção é propiciar luminosidade, propiciando dialogicidade, instigando os professores a olhar para si, rebuscando vivências avaliativas autônomas, ainda não refletidas, fronteiras que muitas vezes impedem a criação de outros jeitos de caminhar. Acreditamos que, no meio da viela, sempre haverá esperança, cabe ao artista do tempo observar, ler e interpretar os contornos e as belezas infinitas presentes no contexto das salas de aula e, entre elas, deixar espaço para esperançar, interrogar e fazer ressurgir um novo jeito para avaliar.

\section{Referências}

BENVENUTTI, D. B. Avaliação de aprendizagens: relações entre formação inicial e práticas adotadas por professoras pedagogas dos anos iniciais da educação Básica. Tese (Doutorado em Educação) - Universidade Regional do Noroeste do Estado do Rio Grande do Sul, Ijuí, 2016.

BRASIL. Lei no 9.394, de 24 de dezembro de 1996. Estabelece as diretrizes e bases da educação nacional. Brasília, DF, 1996.

CAPLAN, S. Using focus group methodology for ergonomic design. Ergonomics, London, v. 33, n. 5, p. 527-533, 1990.

FORMOSINHO, J. Formação de professores: aprendizagem profissional e acção docente. Porto, Portugal: Porto Editora, 2009.

FREIRE, P. Conscientização: teoria e prática da libertação - uma introdução ao pensamento de Paulo Freire. 3. ed. São Paulo: Centauro, 2006.

. Educação e mudança. São Paulo: Paz e Terra, 2014.

O papel da educação na humanização. Revista Paz e Terra, São Paulo, a. IV, n. 9, p. 123-132, out. 1969. $\overline{\text { ra, } 1996 .}$

. Pedagogia da autonomia: saberes necessários à prática educativa. São Paulo: Paz e Ter-

. Pedagogia da esperança: um reencontro com a pedagogia do oprimido. 11. ed. Rio de Janeiro: Paz e Terra, 2003. 
. Pedagogia do oprimido. 45. ed. Rio de Janeiro: Paz e Terra, 2005.

Professora SIM tia NÃO - cartas a quem ousa ensinar. São Paulo: Olho d’Água, 1993.

GIL, A. C. Métodos e técnicas de pesquisa social. São Paulo: Atlas, 1999.

LOPES, C. O fórum de discussão como espaço de intersubjetividade e perspectivas de pesquisa. In: ENCONTRO NACIONAL SOBRE HIPERTEXTO, 2., 2007, Fortaleza. Anais... Fortaleza: UFPE, 2007. Disponível em: <http://www.ufpe.br/nehte/hipertexto2007/anais/ANAIS/Art48_Lopes.swf>. Acesso em: 31 maio 2017.

SCHÖN, D. A. Educando o profissional reflexivo: um novo design para o ensino e a aprendizagem. Trad. Roberto Cataldo Costa. Porto Alegre: Artmed, 2000. 